\title{
Elevated Incidence of Fractures in Solid-Organ Transplant Recipients on Glucocorticoid-Sparing Immunosuppressive Regimens
}

\author{
B. J. Edwards, ${ }^{1}$ A. Desai, ${ }^{2}$ J. Tsai, ${ }^{1}$ H. Du, ${ }^{2}$ G. R. Edwards, ${ }^{1}$ A. D. Bunta, ${ }^{1}$ A. Hahr, ${ }^{1}$ \\ M. Abecassis, ${ }^{3}$ and S. Sprague ${ }^{2}$ \\ ${ }^{1}$ Bone Health and Osteoporosis Center, Feinberg School of Medicine, Northwestern University, Chicago, IL 60611, USA \\ ${ }^{2}$ NorthShore University HealthSystem, Evanston, IL 60201, USA \\ ${ }^{3}$ Kovler Transplant Center, Feinberg School of Medicine, Northwestern University, Chicago, IL 60611, USA
}

Correspondence should be addressed to B. J. Edwards, bje168@northwestern.edu

Received 11 February 2011; Revised 26 May 2011; Accepted 14 June 2011

Academic Editor: Pawel Szulc

Copyright ( 2011 B. J. Edwards et al. This is an open access article distributed under the Creative Commons Attribution License, which permits unrestricted use, distribution, and reproduction in any medium, provided the original work is properly cited.

This study was conducted to assess the occurrence of fractures in solid-organ transplant recipients. Methods. Medical record review and surveys were performed. Patients received less than 6 months of glucocorticoids. Results. Of 351 transplant patients, 175 patients provided fracture information, with 48 (27.4\%) having fractured since transplant (2-6 years). Transplants included 19 kidney/liver (50\% male), 47 kidney/pancreas (53\% male), 92 liver (65\% male), and 17 pancreas transplants (41\% male). Age at transplant was $50.8 \pm 10.3$ years. Fractures were equally seen across both genders and transplant types. Calcium supplementation $(n=94)$ and bisphosphonate therapy $(n=52)$ were observed, and an association with a lower risk of fractures was noted for bisphosphonate users (OR $=0.45$ 95\% C.I. 0.24, 0.85). Fracture location included $8(16.7 \%)$ foot, $12(25.0 \%)$ vertebral, $3(6.3 \%)$ hand, $2(4.2 \%)$ humerus, $5(10.4 \%)$ wrist, $10(20.8 \%)$ fractures at other sites, and $7(14.6 \%)$ multiple fractures. The estimated relative risk of fracture was nearly seventeen-times higher in male liver transplant recipients ages 45-64 years compared with the general male population, and comparable to fracture rates on conventional immunosuppressant regimens. Conclusion. We identify a high frequency of fractures in transplant recipients despite limited glucocorticoid use.

\section{Introduction}

Within the past 3 decades, organ transplantation has become an established therapy for end-stage diseases of the kidney, liver, and lung. Survival after solid-organ transplantation has improved markedly mainly because of the addition of calcineurin inhibitors, cyclosporine A (CsA), and tacrolimus, to posttransplantation immunosuppressive regimens. With improved survival has come a greater appreciation of complications such as osteoporosis and fractures that negatively influence patients' quality of life. The pathogenesis of transplantation osteoporosis is complex and incompletely understood. It is probably related to a combination of noxious effects to the skeleton that occur both before and after organ transplantation. Cardiac, kidney, lung, and liver failure each have unique pathophysiologies that influence bone and mineral metabolism before transplantation. Additional factors such as aging, nutritional deficiencies, immobility, diabetes mellitus, tobacco, and alcohol may affect the skeletons of these transplant recipients before and after transplantation. In the posttransplant period, patients are then subjected to a drug regimen that usually includes high doses of glucocorticoids, the most common cause of secondary osteoporosis. Glucocorticoids are prescribed in combination with other immunosuppressive agents, such as calcineurin inhibitors (cyclosporine A or tacrolimus), rapamycin, mycophenylate mofetil, and azathioprine. Of these agents, both cyclosporine A and tacrolimus are thought to have specific adverse effects upon skeletal integrity. It is thought that the independent and interconnected skeletal 
effects of glucocorticoids and calcineurin inhibitors lead to a form of bone disease characterized by rapid bone loss and high rates of fractures [1-6].

While most transplant centers have used triple therapy consisting of a calcineurin-inhibitor (CNI), an antimetabolite, and steroids as induction and maintenance regimens, steroid sparing regimens have been developed due to the concern in the transplant community about the importance of steroid-related morbidity $[7,8]$. The purpose of this study was, therefore, to evaluate whether glucocorticoid-sparing immunesuppressive regimens are associated with a reduced risk of fractures. Our prior work has shown that conventional immunosuppressant regimens were associated with a 13 -fold higher risk of fracture than age- and gender-matched rates form a nationally representative sample (National Health Interview Survey).

\section{Materials and Methods}

2.1. Patients. The Kovler Transplant Center at Northwestern University is located at Northwestern Memorial Hospital. An extensive clinical database is maintained at Northwestern Memorial Hospital. The status of all patients in the database is maintained as part of the regular posttransplantation care at the respective hospitals. The Institutional Review Board approved this study and all participants provided informed consent.

Inclusion. 18 years of age and older recipients of solidorgan transplants between January 1, 2001 and December 31,2007 , survivals for at least 2 years after transplant. Use of glucocorticoids limited to the initial 6 months of immunosuppressive regimen.

Exclusion. prolonged glucocorticoid therapy, inability to provide informed consent, fractures of digits or toes, and skull fractures. The cohort for this study includes 351 patients who received pancreas, kidney-pancreas, and liver transplants and survived. Adequate fracture information was obtained in 175 subjects. There were 92 liver, 47 kidneypancreas, 19 kidney-liver, and 17 pancreas transplants preformed and evaluable during the study interval. Kidney-only transplants and cardiac transplants were excluded due to prolonged glucocorticoid use.

2.2. Fracture Ascertainment and Verification. Information in symptomatic incident fractures was obtained retrospectively in the organ transplant cohort. All patients were contacted by telephone $(88 \%)$ or at the clinic visit $(12 \%)$ and queried about fracture occurrence since the transplant. All fractures identified were verified by review of the medical record for formal radiographic reports or other relevant documentation. Asymptomatic fractures not located in the thoracic spine/rib cage (visualized on chest X-ray) may have been missed because routine thoracic and lumbar spine films were not obtained for spinal morphometry. Fractures of the face and digits were excluded from analysis.

2.3. Data Analysis. Descriptive statistics such as mean \pm SD (standard deviation) were used to summarize patient characteristics for continuous variables whereas frequency and percentage were used for categorical variables. Incidence rate per person-year of fracture was calculated, using the observed fracture frequency in this study cohort as the numerator, and a product of the individuals at risk and the time units as the denominator. The time units were defined as the years since the transplant till whatever happened first during the followup, fracture date, or the interview date. All interviews were conducted between July 1, 2007 and December 31, 2009. Overall person-year fracture incidence rate was computed, as well the age- and gender-specific person-year fracture incidence rate. Age was also stratified as $<18,18-24,25-44,45-64$, and 65-69, according to 1994 NHIS grouping. Organ-, age-, and gender-specific numbers and rates, and person-years of observation were calculated. Weighted age- and gender-specific fracture rates from 1994 NHIS (National Health Interview Survey) were applied to the number of person-years of observation for each organspecific age and gender category of transplant patients to calculate an expected number of fractures. The ratio (expressed as an estimated relative risk) of observed and expected number of fractures was used to compare fracture of transplant patients to that of the national sample of the 1994 NHIS.

A Chi-square or Fisher's exact test was used to assess the association between categorical variables (i.e., gender) and the occurrence of fracture. A two-sample $t$-test was used to assess the difference between fractured and nonfractured subjects, with respect to continuous variables (i.e., age at transplant). Time to event analysis was applied to estimate the average time to fracture after transplant among organ transplant recipients. Kaplan-Meier plot was used to depict the time to fracture difference between male and female, between age at transplant $\geq 45$ and $<45$ patients, and among organ transplant types. Log-rank test was used to determine the $P$ values. A two-sided significance level 0.05 was used. Data were stored in excel format, and the statistical analysis was carried out using SAS 9.1.

\section{Results}

The specific patient characteristics stratified by type of organ transplant are shown in Table 1. Of 298 transplant patients (Jan 2001-Dec 2007), 175 patients provided fracture information, with $48(59 \%)$ having fractured since transplant (2-6 years). Nonrespondents were similar in demographic characteristics as well as comorbidities. Calcium supplementation $(n=94)$ and bisphosphonate therapy $(n=$ 52) were observed and an association with a lower risk of fractures was noted for bisphosphonate users (OR 0.45 95\% C.I. 0.24, 0.85). Transplants included 19 kidney/liver (50\% male), 47 kidney/pancreas (53\% male), 92 liver (65\% male), and 17 pancreas transplants (41\% male). Age at transplant was similar $(P=0.146)$ in fracture $(47.8 \pm 11.3$ years $)$ and nonfracture groups $(50.4 \pm 10.0 \mathrm{yrs})$. Fractures were equally seen $(P=0.224)$ in both genders ( 23 of 71 female $(32.4 \%)$ and 25 of 104 male $(24.0 \%))$. Fractures were equally distributed $(P=0.582)$ across all transplant types $(15.8 \%$, $29.8 \%, 27.2 \%$, and $35.3 \%$, resp.). Fracture location included 
TABLE 1: Characteristics of organ transplant recipients and patients with fractures.

\begin{tabular}{|c|c|c|c|c|}
\hline Patient features & Kidney/liver & Kidney/pancreas & Liver & Pancreas \\
\hline Number of patients & 19 & 47 & 92 & 17 \\
\hline Gender ( $\%$ female $)$ & 52.6 & 46.8 & 35 & 58.8 \\
\hline Age at transplant in years $($ mean $\pm \mathrm{SD})(n)$ & $54.9 \pm 7.5$ & $43.9 \pm 8.2$ & $53.2 \pm 10.3$ & $41.1 \pm 7.3$ \\
\hline Number with fractures & 4 & 15 & 22 & 7 \\
\hline \multirow[t]{2}{*}{ Men } & $1 / 9$ & $7 / 25$ & $16 / 60$ & $1 / 7$ \\
\hline & $11 \%$ & $28 \%$ & $27 \%$ & $14 \%$ \\
\hline \multirow[t]{2}{*}{ All women } & $3 / 10$ & $8 / 22$ & $6 / 32$ & $6 / 10$ \\
\hline & $30 \%$ & $32 \%$ & $19 \%$ & $60 \%$ \\
\hline \multirow[t]{2}{*}{ Postmenopausal women $* *$} & $2 / 10$ & $5 / 22$ & $5 / 22$ & $0 / 1$ \\
\hline & $20 \%$ & $23 \%$ & $23 \%$ & $0 \%$ \\
\hline
\end{tabular}

${ }^{* *}$ Menopause assumed if age at fracture $\geq 50$ years.

TABLE 2: Age- and gender-specific fracture incidence rates in all transplant recipients.

\begin{tabular}{|c|c|c|c|c|c|c|c|c|}
\hline \multirow[b]{2}{*}{ Age in years } & \multicolumn{4}{|c|}{ Women } & \multicolumn{4}{|c|}{ Men } \\
\hline & $\begin{array}{c}\text { Person-years } \\
\text { at risk }\end{array}$ & $\begin{array}{l}\text { Observed } \\
\text { number of } \\
\text { fractures }\end{array}$ & $\begin{array}{l}\text { Expected } \\
\text { number of } \\
\text { fracture }\end{array}$ & $\begin{array}{l}\text { Estimated } \\
\text { relative risk }\end{array}$ & $\begin{array}{c}\text { Person-years } \\
\text { at risk }\end{array}$ & $\begin{array}{l}\text { Observed } \\
\text { number of } \\
\text { fractures }\end{array}$ & $\begin{array}{l}\text { Expected } \\
\text { number of } \\
\text { fractures }\end{array}$ & $\begin{array}{l}\text { Estimated } \\
\text { relative risk }\end{array}$ \\
\hline$<18$ & 0 & 0 & - & - & 0 & 0 & - & - \\
\hline $18-24$ & 2.8 & 1 & - & - & 0 & 0 & - & - \\
\hline $25-44$ & 106.1 & 6 & 0.33 & 18.2 & 127.0 & 9 & 0.83 & 10.9 \\
\hline $45-64$ & 155.1 & 16 & 0.47 & 34.4 & 280.3 & 12 & 0.81 & 14.8 \\
\hline $65-69$ & 14.1 & 0 & 0.06 & 0 & 31.1 & 3 & 0.09 & 0 \\
\hline
\end{tabular}

TABle 3: Age and gender specific fracture incidence rates in the US population. National Center for Health Statistics, National Health Interview Survey (NHIS) 1994.

\begin{tabular}{lcc}
\hline Age in Years & Women & Men \\
\hline$<18$ & 5.9 & 10.7 \\
$18-24$ & 1.8 & 10.3 \\
$25-44$ & 3.1 & 6.5 \\
$45-64$ & 3.0 & 2.9 \\
$65-69$ & 4.6 & 2.8 \\
\hline
\end{tabular}

$8(17.5 \%)$ foot (metatarsal), $8(16.7 \%)$ vertebral, $12(25.0 \%)$ vertebral, $(6.25 \%)$ hand $3,2(4.2 \%)$ humerus, $5(10.4 \%)$ wrist fractures, $10(20.8 \%)$ occurred at other sites, and 7 (14.6\%) occurred at multiple sites (Figure 1). Of the 25 men with fractures, the incidence of fractures was 0.065 per person-year among the 733.8 person-years of observation.

Patient characteristics were stratified by type of organ transplant (Table 1). Four (21\%) of the 19 kidney-liver transplant recipients had symptomatic initial fractures during the 76.9 person-years of observation for a crude fracture rate of 0.039 per year of observation. The mean age at the time of the initial symptomatic fracture was $56.5 \pm$ 9.2 years (median: 58; range: 47-65), and the mean time from transplant to initial fracture was $54.1 \pm 18.8$ months (median: 54; range: $41-67)$. Both axial $(n=2)$ and limb $(n=1)$ fractures occurred in this small group.

Fifteen of 47 kidney-pancreas (32\%) recipients had their initial symptomatic fracture during the 207.1 person-years

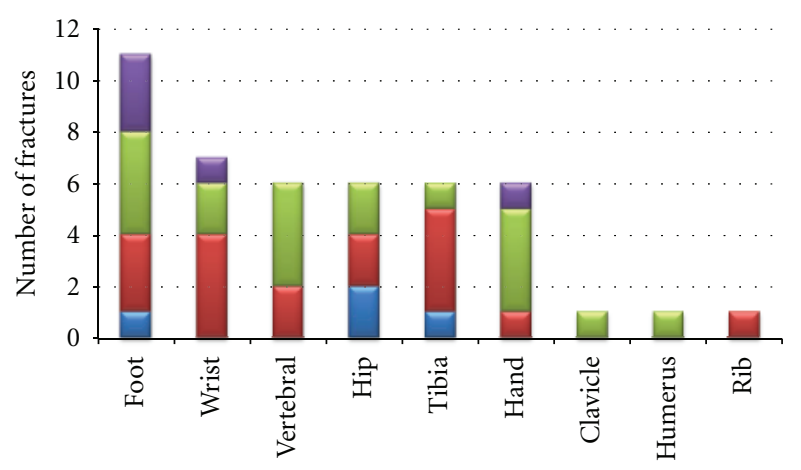

Type of fracture

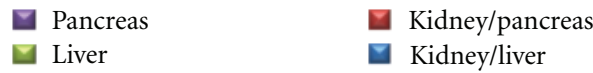

FIGURE 1: Type of fracture by type of solid-organ transplant.

of observation for a crude fracture rate of 0.068 per year of observation. The mean age at the time of initial fracture was $48.3 \pm 9.3$ years, (median: 50 ; range: $32-63$ ), and the mean number of months from transplant to initial fracture was $51.0 \pm 23.2$ months (median: 59; range: 5-80). The most common site of fracture in this group was the foot, and occurred equally in males and females $28.0 \%$ versus $31.8 \%$, respectively. Five axial (rib and spine) fractures occurred compared with 7 limb fractures in this group as compared to 15 limb fractures. Two of the 3 patients who reported multiple fractures were women. 
TABle 4: Age- and gender-specific fracture incidence rates in kidney/liver transplant recipients.

\begin{tabular}{|c|c|c|c|c|c|c|c|c|}
\hline \multirow[b]{2}{*}{ Age in years } & \multicolumn{4}{|c|}{ Women } & \multicolumn{4}{|c|}{ Men } \\
\hline & $\begin{array}{c}\text { Person-years } \\
\text { at risk }\end{array}$ & $\begin{array}{l}\text { Observed } \\
\text { number of } \\
\text { fractures }\end{array}$ & $\begin{array}{l}\text { Expected } \\
\text { number of } \\
\text { fractures }\end{array}$ & $\begin{array}{l}\text { Estimated } \\
\text { relative risk }\end{array}$ & $\begin{array}{c}\text { Person-years } \\
\text { at risk }\end{array}$ & $\begin{array}{l}\text { Observed } \\
\text { number of } \\
\text { fractures }\end{array}$ & $\begin{array}{l}\text { Expected } \\
\text { number of } \\
\text { fractures }\end{array}$ & $\begin{array}{l}\text { Estimated } \\
\text { relative risk }\end{array}$ \\
\hline$<18$ & 0 & 0 & - & - & 0 & 0 & - & - \\
\hline $18-24$ & 0 & 0 & - & - & 0 & 0 & - & - \\
\hline $25-44$ & 7.0 & 0 & 0.02 & 0 & 5.5 & 0 & 0.04 & 0 \\
\hline $45-64$ & 30.1 & 2 & 0.09 & 22.1 & 28.8 & 2 & 0.08 & 12.0 \\
\hline $65-69$ & 5.3 & 0 & 0.02 & 0 & 0 & 0 & - & - \\
\hline
\end{tabular}

TABLE 5: Age- and gender-specific fracture incidence rates in kidney/pancreas transplant recipients.

\begin{tabular}{|c|c|c|c|c|c|c|c|c|}
\hline \multirow[b]{2}{*}{ Age in years } & \multicolumn{4}{|c|}{ Women } & \multicolumn{4}{|c|}{ Men } \\
\hline & $\begin{array}{c}\text { Person-years } \\
\text { at risk }\end{array}$ & $\begin{array}{l}\text { Observed } \\
\text { number of } \\
\text { fractures }\end{array}$ & $\begin{array}{l}\text { Expected } \\
\text { number of } \\
\text { fractures }\end{array}$ & $\begin{array}{l}\text { Estimated } \\
\text { relative risk }\end{array}$ & $\begin{array}{l}\text { Person-years } \\
\text { at risk }\end{array}$ & $\begin{array}{l}\text { Observed } \\
\text { number of } \\
\text { fractures }\end{array}$ & $\begin{array}{l}\text { Expected } \\
\text { number of } \\
\text { fractures }\end{array}$ & $\begin{array}{l}\text { Estimated } \\
\text { relative risk }\end{array}$ \\
\hline$<18$ & 0 & 0 & - & - & 0 & 0 & - & - \\
\hline $18-24$ & 0 & 0 & - & - & 0 & 0 & - & - \\
\hline $25-44$ & 44.5 & 2 & 0.14 & 7.2 & 62.3 & 4 & 0.40 & 9.9 \\
\hline $45-64$ & 43.8 & 6 & 0.13 & 45.7 & 52.4 & 4 & 0.15 & 26.2 \\
\hline $65-69$ & 0 & 0 & - & - & 0 & 0 & 一 & - \\
\hline
\end{tabular}

Twenty-two $(24 \%)$ of 92 liver transplant recipients had fractures during the 383.3 person-years of observation, for a crude fracture rate of 0.065 per year of observation. The mean age at the time of initial symptomatic fracture was $54.4 \pm 12.2$ years (median: 57 ; range: 25-71), and the mean number of months from transplant $36.0 \pm 28.9$ months (median: 30; range: 3-86). Nine axial (vertebral and hip) fractures occurred compared with 18 limb fractures. Four patients receiving liver transplants sustained multiple fractures.

Seven $(41 \%)$ of the 17 pancreas transplant recipients had fractures during the 66.5 person-years of observation for a crude fracture rate of 0.090 per year of observation. The mean age at the time of initial symptomatic fracture was $40.6 \pm 6.5$ years (median: 42 ; range: $31-50$ ), and the mean number of months from transplant to initial fracture was $41.7 \pm 22.1$ months (median: 42 ; range; $26-57$ ). All 3 fractures in this group were limb fractures ( 1 wrist and 2 foot (metatarsal)), and none sustained multiple fractures.

Age- and gender-specific fracture incidence rates representative of the US civilian, noninstitutionalized population from the 1994 NHIS are shown in Tables 2, 3, 4, 5, 6, and 7. The comparison of age- and gender-specific incidence rates for initial symptomatic fractures in solid-organ transplant recipients and the US population were shown in Tables 3, 4, 5,6 , and 7 .

The male liver transplant recipients aged 45-64 years at the Kovler Transplant Center cohort had 100 person-years of observation. The estimated relative risk of fracture was nearly seventeen-times higher in male liver transplant recipients ages 45-64 years compared with the general male population of those age groups.

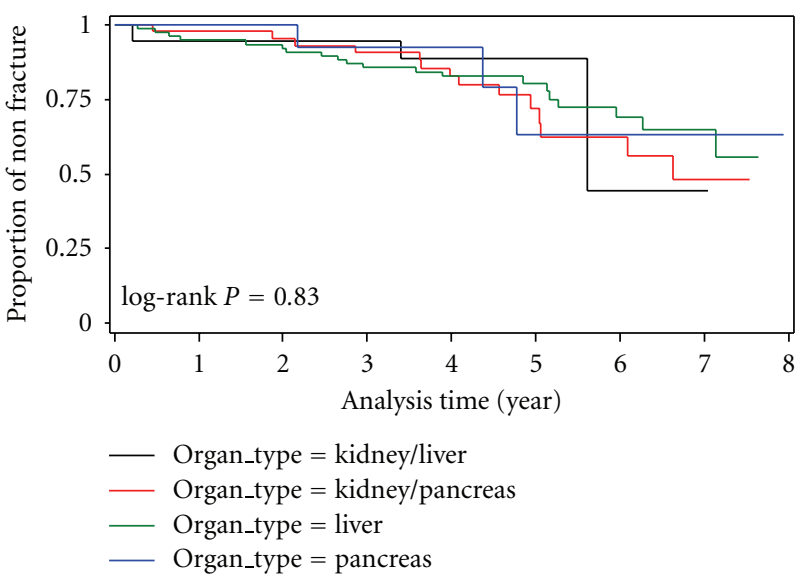

FIgURE 2: Proportion of fracture among all patients over time.

For those 175 transplant recipients who provided valid fracture data (yes or no), the median followup was 4.46 years (range: $0-7.93$ years), 75\% nonfracture time was 5.04 years (95\% confidence interval: $4.08-5.37$ years). Figure 2 demonstrated that among those 175 transplant recipients about 5\% sustained fracture within the first 12 months while by 5 years about $25 \%$ of transplant recipients have sustained a fracture. The time to fracture was not different between females and males, neither between patients with age $<45$ and $\geq 45$ years of age at time of transplant, nor between organ transplant types. 
TABLE 6: Age- and gender-specific fracture incidence rates in liver transplant recipients.

\begin{tabular}{|c|c|c|c|c|c|c|c|c|}
\hline \multirow[b]{2}{*}{ Age in years } & \multicolumn{4}{|c|}{ Women } & \multicolumn{4}{|c|}{ Men } \\
\hline & $\begin{array}{c}\text { Person-years } \\
\text { at risk }\end{array}$ & $\begin{array}{l}\text { Observed } \\
\text { number of } \\
\text { fractures }\end{array}$ & $\begin{array}{l}\text { Expected } \\
\text { number of } \\
\text { fractures }\end{array}$ & $\begin{array}{l}\text { Estimated } \\
\text { relative risk }\end{array}$ & $\begin{array}{l}\text { Person-years } \\
\text { at risk }\end{array}$ & $\begin{array}{l}\text { Observed } \\
\text { number of } \\
\text { fractures }\end{array}$ & $\begin{array}{l}\text { Expected } \\
\text { number of } \\
\text { fractures }\end{array}$ & $\begin{array}{l}\text { Estimated } \\
\text { relative risk }\end{array}$ \\
\hline$<18$ & 0 & 0 & - & - & 0 & 0 & - & - \\
\hline $18-24$ & 2.8 & 1 & 0.005 & 201.5 & 0 & 0 & - & - \\
\hline 25-44 & 33.2 & 1 & 0.10 & 9.7 & 33.3 & 4 & 0.22 & 18.5 \\
\hline $45-64$ & 75.3 & 7 & 0.23 & 31.0 & 189.2 & 6 & 0.55 & 16.4 \\
\hline $65-69$ & 8.8 & 0 & 0.04 & 0 & 31.1 & 3 & 0.09 & 34.5 \\
\hline
\end{tabular}

TABLE 7: Age- and gender-specific fracture incidence rates in pancreas transplant recipients.

\begin{tabular}{lcccccccc}
\hline Age in years & $\begin{array}{c}\text { Person-years } \\
\text { at risk }\end{array}$ & $\begin{array}{c}\text { Observed } \\
\text { number of } \\
\text { fractures }\end{array}$ & $\begin{array}{c}\text { Expected } \\
\text { number of } \\
\text { fractures }\end{array}$ & $\begin{array}{c}\text { Estimated } \\
\text { relative risk }\end{array}$ & $\begin{array}{c}\text { Person-years } \\
\text { at risk }\end{array}$ & $\begin{array}{c}\text { Observed } \\
\text { number of } \\
\text { fractures }\end{array}$ & $\begin{array}{c}\text { Expected } \\
\text { number of } \\
\text { fracture }\end{array}$ & $\begin{array}{c}\text { Estimated } \\
\text { relative risk }\end{array}$ \\
\hline$<18$ & 0 & 0 & - & - & 0 & 0 & - & - \\
$18-24$ & 0 & 0 & - & - & 0 & 0 & - & - \\
$25-44$ & 25.0 & 4 & 0.08 & 51.7 & 25.8 & 2 & 0.17 & 6 \\
$45-64$ & 5.9 & 1 & 0.02 & 56.5 & 9.9 & 0 & 0.03 & 0 \\
$65-69$ & 0 & 0 & - & - & 0 & 0 & - & - \\
\hline
\end{tabular}

\section{Discussion}

This study is the first to quantify the magnitude of excess fractures occurring in solid-organ transplant recipients (liver) on glucocorticoid-sparing immuno-suppressive regimens. An elevated fracture risk (17-fold increased risk of fractures) was identified, in fact, the fracture incidence was similar to our prior studies of transplant recipients on conventional antirejection regimens [9]. As survival after organ transplantation has improved, skeletal complications are becoming increasingly troubling, with some studies showing fracture incidence of $20-40 \%$ post transplant [1012]. Immuno-suppressive regimens with limited glucocorticoid use have been developed in an attempt to minimize adverse events. Prior studies have assessed kidney transplants, showing that glucocorticoid-free protocols have resulted in less bone loss, although fractures have not been reported as primary outcomes [13-15]. Glucocorticoids and calcineurin inhibitors have specific adverse effects on the skeleton [16-18], and have been associated with increased risk for fracture. Glucocorticoids contribute to posttransplant bone loss, especially the rapid loss that occurs in the first 6-12 months, by inhibiting bone formation. Thus, organ transplantation has been revolutionized in the era since the routine use of immune suppressive therapy with glucocorticoids, calcineurin inhibitors (cyclosporine A or tacrolimus), and either mycophenolate mofetil or azathioprine.

Post transplantation osteoporosis is a complex and multifactorial disease with preexisting bone loss associated with end-stage organ failure, immobility, aging, high-dose glucocorticoid use, and immune suppressant therapy having been implicated. End-stage kidney or liver disease, and congestive heart failure are associated with low bone mineral density, fractures, and abnormalities of mineral metabolism [19-23]. Metabolic disturbances such as abnormalities in calcium, phosphorus, and parathyroid hormone persist for many months or years following kidney transplantation [24]. Diabetes mellitus, a common cause for pancreas and kidney transplants, results in alterations in bone metabolism and fractures [19, 25-27]. Hypogonadism common in older males has been associated with bone loss and fractures [2830]. Immobility due to end-stage organ disease has profound effect on bone metabolism [31].

Additionally, we identified that calcium supplementation and vitamin $\mathrm{D}$ was common in transplant recipients, but failed to reduce fracture risk. Bisphosphonate therapy however, was identified as being associated with a reduction in fracture risk. These preliminary findings suggest important treatment options in transplant candidates with suitable kidney function such as CKD stage 2-3 (GFR > $35 \mathrm{cc} / \mathrm{min} / 1.73 \mathrm{~m}^{2}$ ).

Our data on four self-reported symptomatic fractures in 19 liver-kidney transplant recipients represents both genders. Symptomatic axial fractures were less frequently reported than limb fractures. There is a paucity of studies assessing the incidence of fractures in these transplant recipients. All four fractures occurred in patients with pretransplant chronic hepatitis, none of these patients had diabetes mellitus. We reported on 15 fractures occurring in 47 kidney-pancreas recipients, all of whom had diabetes mellitus and end-stage kidney disease. In the kidney pancreas transplant recipients 
followed for a mean time of 6.3 years we noted more limb than axial fractures. Our findings confirm the high incidence of fractures of $20-45 \%$ in prior studies [19, 32-34]. Diabetes mellitus results in low bone formation bone disease, with consequent fractures $[27,35,36]$.

We described 22 symptomatic fractures in 92 liver transplant recipients, this cohort was followed for a mean of 6 years, the crude fracture rate was 0.063 per year. These data are comparable to the frequency of postliver-transplant fractures reported in other studies ranging from 20-40\% [10-12]. Up to $21 \%$ of patient who receive a liver transplant sustain a fracture within the first two years [37]. Thus this data demonstrate that rate of fracture on glucocorticoidsparing regimen remains unchanged. Fractures were most common in patients with hepatocellular carcinoma $(3 / 3$, $100 \%)$, than in patients with chronic hepatitis $(13 / 49,26 \%)$ or alcoholic-induced cirrhosis $(2 / 9,22 \%)$.

We also reported on seven fractures in 17 pancreas transplants with diabetes and followed for a mean of 4 years. The most common site affected was the foot. Patients who received kidney pancreas and pancreas transplants were diabetic and 10 years younger than other solid-organ transplant recipients. In all cases, fractures were limb fractures.

Calcineurin inhibitors have allowed for improved survival and reductions in glucocorticoid therapy in transplantation. However, the calcineurin inhibitors, cyclosporine (CsA), and tacrolimus (FK506) have also been implicated in posttransplant bone disease. These drugs stimulate loss of bone mass independent of glucocorticoid therapy, with high-turnover bone metabolism noted in rat models [3840]. Specifically, CsA administration has resulted in marked increases in bone resorption and formation as well as greater losses of trabecular bone [38-40]. Furthermore, its direct effects on calcineurin genes expressed in osteoclasts may affect bone turnover [41, 42]. FK506 has also been shown in rat models to cause loss of trabecular bone volume in rats [38-40]. Comparison of the two drugs in rat models has demonstrated more severe bone loss with the use of CsA than FK506. In liver transplant patients [43], there is a more favorable long-term effect on bone mass evolution with the use of FK506 up to 2 years posttransplantation [44]. Both have been noted to cause significant bone resorption in kidney transplant recipients [17]. However, FK506 has been noted to protect bone mineral density better than CsA when both have been administered with combined steroid therapy over 1 year [45]. Less is understood of the effects of other immunosuppressive agents on bone loss. Few studies have evaluated the effects of mycophenolate mofetil (MMF) and sirolimus on bone metabolism [46]. In rat models, shortterm use of MMF did not result in decreased bone volume $[46,47]$. In humans, comparison of CsA to sirolimus resulted in less bone turnover and less bone resorption with sirolimus [47] in the short term. Longer-term data is warranted.

There are several limitations with this analysis as comparisons between the fracture rates in the transplant cohort and the NHIS data should be interpreted with caution. First, the NHIS data includes self-reported fractures that were not verified. We used a more stringent case finding procedure in the transplant cohort as we verified the patient's self-report of fracture. Thus, our observed number of fractures is more conservative than the NHIS data. Second, the number of person-years of observation in some of our strata are small, especially for kidney pancreas and kidney-liver recipients. Thus, the expected number of fractures are small, resulting in relative risk estimates that are unstable and liable to inflation from a very small number of events. Thus, we did not use test of significance for these results. Fractures rates for patients included only the initial posttransplant fracture while some patients experienced more than one fracture. Therefore, the number of fracture events in the transplant cohort represent the lowest estimate of the problem. In the strata with at least 100 person-years, we determined that fractures in transplant patients were increased nearly seventeen-fold compared with expected numbers from national data. The frequency of fractures in this transplant cohort clearly represent the lower boundary of the problem because routine surveillance for asymptomatic vertebral fractures was not performed. Nevertheless, using our conservative estimate from the occurrence of symptomatic fractures, these data demonstrate the magnitude of this excess risk.

There is limited information in medical records about potential risk factors for increased fracture rate observed in this study. Previous studies of those risk factors reveal inconsistent findings. For kidney transplant patients, risk factors associated with fracture included low BMD, prior parathyroidectomy, higher glucocorticoid use, and longer interval between transplant and fracture [48]. A populationbased study showed that age and diabetic nephropathy were independent predictors of fracture risk while higher activity status was protective [49]. Future well characterized studies will allow better definition of specific risk factors for transplant-related fractures in this heterogeneous cohort.

Patients with kidney/pancreas and pancreas transplantation appear to be at higher risk of fracture. Diabetics are predisposed to low bone turnover bone disease, neuropathy, and osteopenia. Factors uniquely associated with osteopenia in diabetics include chronic hypocalcemia, insulin deficiency, hypomagnesemia, relative hypoparathyroidism, negative protein balance, immobility, hypogonadism, and metabolic acidosis $[19,27,35,36]$.

In liver transplant recipients, initial BMD, interval change in $\mathrm{BMD}$, menopause, primary biliary cirrhosis, longterm glucocorticoid use, calcineurin inhibitors, underlying pretransplant disease severity, multiple fractures, and pretransplant fracture have been identified as risk factors for fractures $[10,22,37,50]$.

\section{Conclusion}

This study is the first to quantify the magnitude of excess fractures occurring in solid-organ transplant recipients on glucocorticoid-sparing immuno-suppressive regimens. Liver transplant recipients have a 17 -fold increased risk of fractures as compared to age- and gender-matched controls. Additional research must be conducted to clarify pathogenesis of bone loss and fractures and the development of suitable preventive strategies. 


\section{Abbreviations}

CsA: Cyclosporine

FK506: Tacrolimus

MMF: Mycophenolate mofetil

CNI: Calcineurin inhibitor

NHIS: National Health Interview Survey.

\section{Conflict of Interests}

A. Desai, J. Tsai, H. Du, G. R. Edwards, A. D. Bunta, A. Hahr, M. Abecassis, and S. Sprague declare no conflict of interests.

\section{Acknowledgments}

Funding was provided by the Alliance for Bone Health. The authors retained full independence in study design and analysis. B. J. Edwards works as a consultant at Eli Lilly, Amgen, Warner Chilcott.

\section{References}

[1] A. Cohen and E. Shane, "Osteoporosis after solid organ and bone marrow transplantation," Osteoporosis International, vol. 14, no. 8, pp. 617-630, 2003.

[2] A. Cohen, P. Sambrook, and E. Shane, "Management of bone loss after organ transplantation," Journal of Bone and Mineral Research, vol. 19, no. 12, pp. 1919-1932, 2004.

[3] N. M. Maalouf and E. Shane, "Clinical review: osteoporosis after solid organ transplantation," Journal of Clinical Endocrinology and Metabolism, vol. 90, no. 4, pp. 2456-2465, 2005.

[4] K. Martin, Z. Al-Aly, and E. A. Gonzalez, "Renal osteodystrophy," in Primer on the Metabolic Bone Disease and Disorders of Mineral Metabolism, M. Favus, Ed., pp. 359-366, Philadelphia, $\mathrm{Pa}$, USA, American Society of Bone and Mineral Research, 2006.

[5] E. Shane, M. Rivas, R. B. Staron et al., "Fracture after cardiac transplantation: a prospective longitudinal study," Journal of Clinical Endocrinology and Metabolism, vol. 81, no. 5, pp. 1740-1746, 1996.

[6] S. M. Sprague and M. A. Josephson, "Bone disease after kidney transplantation," Seminars in Nephrology, vol. 24, no. 1, pp. 82-90, 2004.

[7] D. E. Hricik, M. A. O’Toole, J. A. Schulak, and J. Herson, "Steroid-free immunosuppression in cyclosporine-treated renal transplant recipients: a meta-analysis," Journal of the American Society of Nephrology, vol. 4, no. 6, pp. 1300-1305, 1993.

[8] EBPG Expert Group on Renal Transplantation, "European best practice guidelines for renal transplantation. Section IV: long-term management of the transplant recipient. IV.3.1 Long-term immunosuppression. Late steroid or cyclosporine withdrawal," Nephrology, Dialysis, Transplantation, vol. 17, supplement 4, pp. 19-20, 2002.

[9] R. Ramsey-Goldman, J. E. Dunn, D. D. Dunlop et al., "Increased risk of fracture in patients receiving solid organ transplants," Journal of Bone and Mineral Research, vol. 14, no. 3, pp. 456-463, 1999.

[10] M. M. J. Guichelaar, J. Schmoll, M. Malinchoc, and J. E. Hay, "Fractures and avascular necrosis before and after orthotopic liver transplantation: long-term follow-up and predictive factors," Hepatology, vol. 46, no. 4, pp. 1198-1207, 2007.

[11] J. Collier, "Bone disorders in chronic liver disease," Hepatology, vol. 46, no. 4, pp. 1271-1278, 2007.

[12] E. J. Carey, V. Balan, W. K. Kremers, and J. E. Hay, "Osteopenia and osteoporosis in patients with end-stage liver disease caused by hepatitis $\mathrm{C}$ and alcoholic liver disease: not just a cholestatic problem," Liver Transplantation, vol. 9, no. 11, pp. 1166-1173, 2003.

[13] J. V. Torregrosa, J. M. Campistol, M. Montesinos et al., "Factors involved in the loss of bone mineral density after renal transplantation," Transplantation Proceedings, vol. 27, no. 4, pp. 2224-2225, 1995.

[14] H. D. McIntyre, B. Menzies, R. Rigby, D. A. Perry-Keene, C. M. Hawley, and I. R. Hardie, "Long-term bone loss after renal transplantation: comparison of immmunosuppressive regimens," Clinical Transplantation, vol. 9, no. 1, pp. 20-24, 1995.

[15] A. M. Cueto-Manzano, S. Konel, V. Crowley et al., "Bone histopathology and densitometry comparison between cyclosporine a monotherapy and prednisolone plus azathioprine dual immunosuppression in renal transplant patients," Transplantation, vol. 75, no. 12, pp. 2053-2058, 2003.

[16] A. Angeli, G. Guglielmi, A. Dovio et al., "High prevalence of asymptomatic vertebral fractures in post-menopausal women receiving chronic glucocorticoid therapy: a cross-sectional outpatient study," Bone, vol. 39, no. 2, pp. 253-259, 2006.

[17] G. Bozkaya, A. Nart, A. Uslu et al., "Impact of calcineurin inhibitors on bone metabolism in primary kidney transplant patients," Transplantation Proceedings, vol. 40, no. 1, pp. 151$155,2008$.

[18] S. Giannini, M. Nobile, and L. Sartori, "Organ transplantation and glucocorticoid-induced osteoporosis," Frontiers of Hormone Research, vol. 30, pp. 94-106, 2002.

[19] M. Y. Chiu, S. M. Sprague, D. S. Bruce, E. Steve Woodle, J. R. Thistlethwaite, and M. A. Josephson, "Analysis of fracture prevalence in kidney-pancreas allograft recipients," Journal of the American Society of Nephrology, vol. 9, no. 4, pp. 677-683, 1998.

[20] A. M. Alem, D. J. Sherrard, D. L. Gillen et al., "Increased risk of hip fracture among patients with end-stage renal disease," Kidney International, vol. 58, no. 1, pp. 396-399, 2000.

[21] S. D. Roe, C. J. Porter, I. M. Godber, D. J. Hosking, and M. J. Cassidy, "Reduced bone mineral density in male renal transplant recipients: evidence for persisting hyperparathyroidism," Osteoporosis International, vol. 16, no. 2, pp. 142-148, 2005.

[22] M. Ninkovic, S. J. Skingle, P. W. P. Bearcroft, N. Bishop, G. J. M. Alexander, and J. E. Compston, "Incidence of vertebral fractures in the first three months after orthotopic liver transplantation," European Journal of Gastroenterology and Hepatology, vol. 12, no. 8, pp. 931-935, 2000.

[23] A. H. Lee, R. L. Mull, G. F. Keenan et al., "Osteoporosis and bone morbidity in cardiac transplant recipients," American Journal of Medicine, vol. 96, no. 1, pp. 35-41, 1994.

[24] S. M. Sprague, V. Belozeroff, M. D. Danese, L. P. Martin, and K. Olgaard, "Abnormal bone and mineral metabolism in kidney transplant patients-a review," American Journal of Nephrology, vol. 28, no. 2, pp. 246-253, 2008.

[25] A. Saller, S. Maggi, G. Romanato, P. Tonin, and G. Crepaldi, "Diabetes and osteoporosis," Aging: Clinical and Experimental Research, vol. 20, no. 4, pp. 280-289, 2008.

[26] S. Epstein and D. LeRoith, "Diabetes and fragility fractures-a burgeoning epidemic?” Bone, vol. 43, no. 1, pp. 3-6, 2008. 
[27] L. J. Melton III, C. L. Leibson, S. J. Achenbach, T. M. Therneau, and S. Khosla, "Fracture risk in type 2 diabetes: update of a population-based study," Journal of Bone and Mineral Research, vol. 23, no. 8, pp. 1334-1342, 2008.

[28] M. J. Välimäki, K. Kinnunen, L. Volin et al., "A prospective study of bone loss and turnover after allogeneic bone marrow transplantation: effect of calcium supplementation with or without calcitonin," Bone Marrow Transplantation, vol. 23, no. 4, pp. 355-361, 1999.

[29] J. S. Tenover, "Declining testicular function in aging men," International Journal of Impotence Research, vol. 15, no. 4, pp. S3-S8, 2003.

[30] N. Napoli, R. Faccio, V. Shrestha, S. Bucchieri, G. B. Rini, and R. Armamento-Villareal, "Estrogen metabolism modulates bone density in men," Calcified Tissue International, vol. 80, no. 4, pp. 227-232, 2007.

[31] M. Weiss, R. Yogev, and E. Dolev, "Occupational sitting and low hip mineral density," Calcified Tissue International, vol. 62, no. 1, pp. 47-50, 1998.

[32] Y. F. Smets, J. W. de Fijter, J. Ringers, H. H. Lemkes, and N. A. Hamdy, "Long-term follow-up study on bone mineral density and fractures after simultaneous pancreas-kidney transplantation," Kidney international, vol. 66, no. 5, pp. 20702076, 2004.

[33] Y. F. C. Smets, J. W. Van Der Piji, J. W. De Fijter, J. Ringers, H. H. P. J. Lemkes, and N. A. T. Hamdy, "Low bone mass and high incidence of fractures after successful simultaneous pancreaskidney transplantation," Nephrology Dialysis Transplantation, vol. 13, no. 5, pp. 1250-1255, 1998.

[34] D. S. Bruce, K. A. Newell, M. A. Josephson et al., "Long-term outcome of kidney-pancreas transplant recipients with good graft function at one year," Transplantation, vol. 62, no. 4, pp. 451-456, 1996.

[35] M. Janghorbani, R. M. Van Dam, W. C. Willett, and F. B. Hu, "Systematic review of type 1 and type 2 diabetes mellitus and risk of fracture," American Journal of Epidemiology, vol. 166, no. 5, pp. 495-505, 2007.

[36] A. Rakel, O. Sheehy, E. Rahme, and J. LeLorier, "Does diabetes increase the risk for fractures after solid organ transplantation? A nested case-control study," Journal of Bone and Mineral Research, vol. 22, no. 12, pp. 1878-1884, 2007.

[37] G. Leidig-Bruckner, S. Hosch, P. Dodidou et al., "Frequency and predictors of osteoporotic fractures after cardiac or liver transplantation: a follow-up study," Lancet, vol. 357, no. 9253, pp. 342-347, 2001.

[38] S. Epstein, "Post-transplantation bone disease: the role of immunosuppressive agents and the skeleton," Journal of Bone and Mineral Research, vol. 11, no. 1, pp. 1-7, 1996.

[39] S. Kirino, J. Fukunaga, S. Ikegami et al., "Regulation of bone metabolism in immunosuppressant (FK506)-treated rats," Journal of Bone and Mineral Metabolism, vol. 22, no. 6, pp. 554-560, 2004.

[40] M. Cvetkovic, G. N. Mann, D. F. Romero et al., "The deleterious effects of long-term cyclosporine A, cyclosporine $\mathrm{G}$, and FK506 on bone mineral metabolism in vivo," Transplantation, vol. 57, no. 8, pp. 1231-1237, 1994.

[41] E. M. Awumey, B. S. Moonga, B. R. Sodam et al., "Molecular and functional evidence for calcineurin-A $\alpha$ and $\beta$ isoforms in the osteoclast: novel insights into cyclosporin A action on bone resorption," Biochemical and Biophysical Research Communications, vol. 254, no. 1, pp. 248-252, 1999.

[42] L. Sun, L. L. Zhu, N. Zaidi et al., "Cellular and molecular consequences of calcineurin A $\alpha$ gene deletion," Annals of the New York Academy of Sciences, vol. 1116, pp. 216-226, 2007.
[43] T. Inoue, I. Kawamura, M. Matsuo et al., "Lesser reduction in bone mineral density by the immunosuppressant, FK506, compared with cyclosporine in rats," Transplantation, vol. 70, no. 5, pp. 774-779, 2000.

[44] A. Monegal, M. Navasa, N. Guañabens et al., "Bone mass and mineral metabolism in liver transplant patients treated with FK506 or Cyclosporine A," Calcified Tissue International, vol. 68, no. 2, pp. 83-86, 2001.

[45] E. Goffin, J. P. Devogelaer, A. Lalaoui et al., "Tacrolimus and low-dose steroid immunosuppression preserves bone mass after renal transplantation," Transplant International, vol. 15, no. 2-3, pp. 73-80, 2002.

[46] I. R. Dissanayake and S. Epstein, "The fate of bone after renal transplantation," Current Opinion in Nephrology and Hypertension, vol. 7, no. 4, pp. 389-395, 1998.

[47] J. M. Campistol, D. W. Holt, S. Epstein, M. Gioud-Paquet, K. Rutault, and J. T. Burke, "Bone metabolism in renal transplant patients treated with cyclosporine or sirolimus," Transplant International, vol. 18, no. 9, pp. 1028-1035, 2005.

[48] V. Pichette, A. Bonnardeaux, L. Prudhomme, M. Gagné, J. Cardinal, and D. Ouimet, "Long-term bone loss in kidney transplant recipients: a cross-sectional and longitudinal study," American Journal of Kidney Diseases, vol. 28, no. 1, pp. 105-114, 1996.

[49] L. M. Vautour, L. J. Melton, B. L. Clarke, S. J. Achenbach, A. L. Oberg, and J. T. McCarthy, "Long-term fracture risk following renal transplantation: a population-based study," Osteoporosis International, vol. 15, no. 2, pp. 160-167, 2004.

[50] A. Monegal, M. Navasa, N. Guañabens et al., "Osteoporosis and bone mineral metabolism disorders in cirrhotic patients referred for orthotopic liver transplantation," Calcified Tissue International, vol. 60, no. 2, pp. 148-154, 1997. 


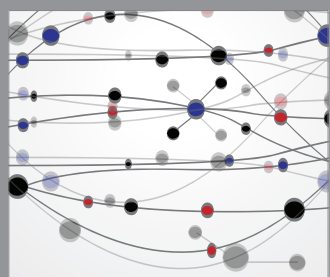

The Scientific World Journal
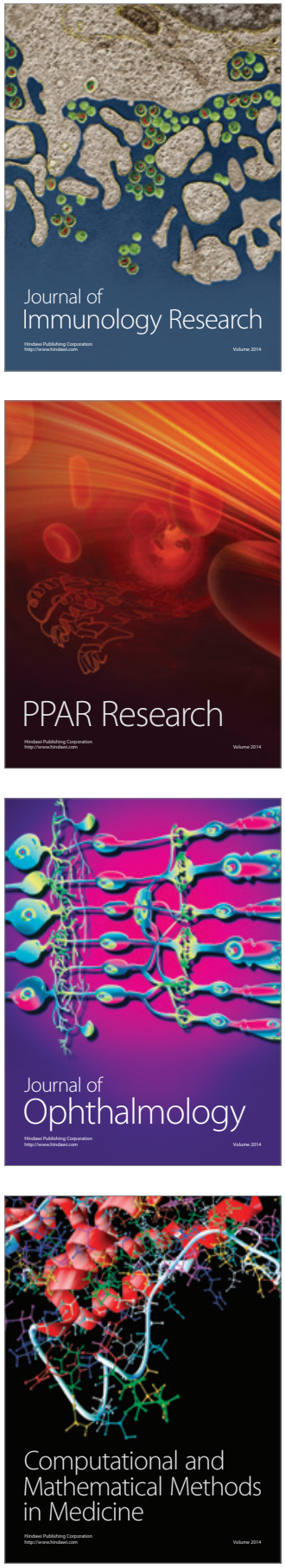

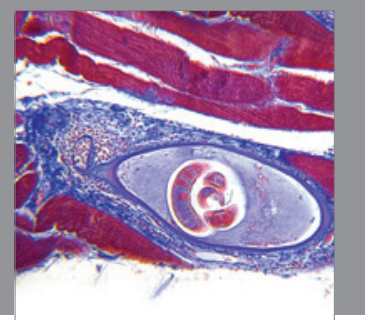

Gastroenterology

Research and Practice
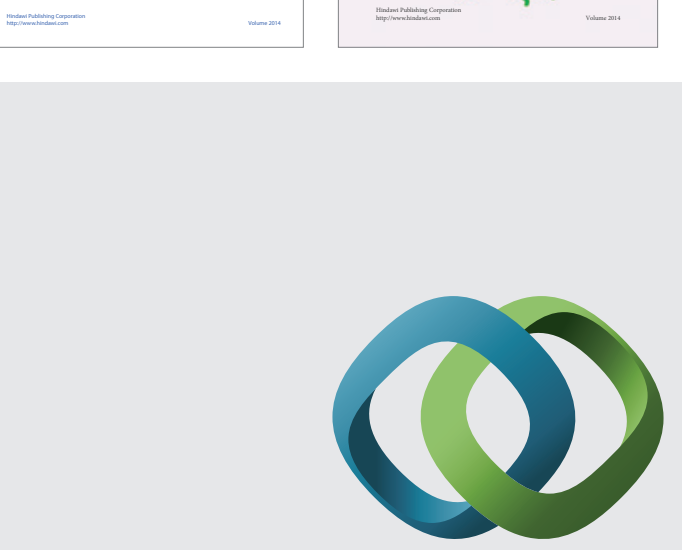

\section{Hindawi}

Submit your manuscripts at

http://www.hindawi.com
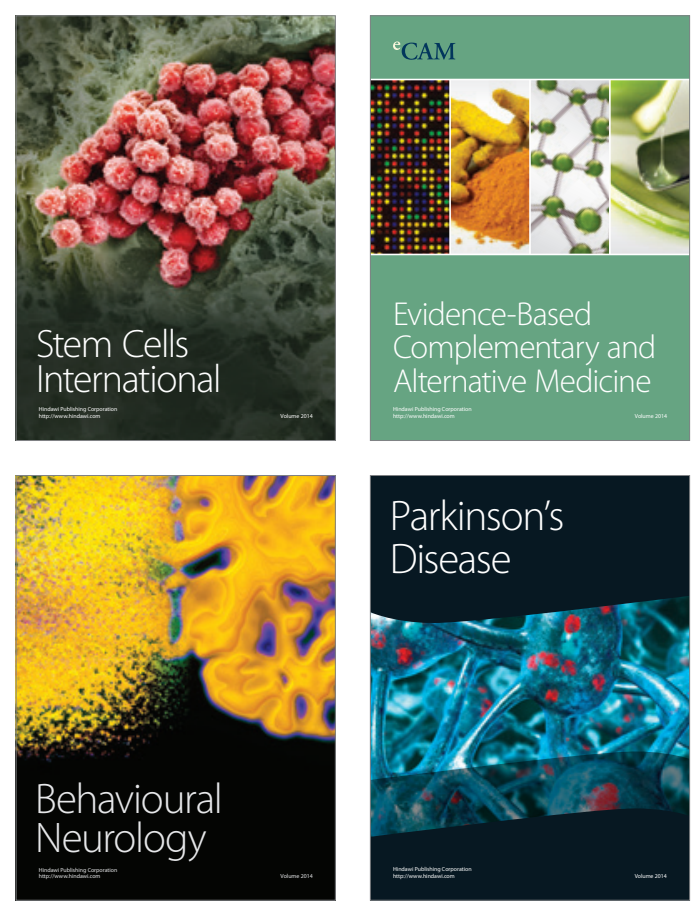

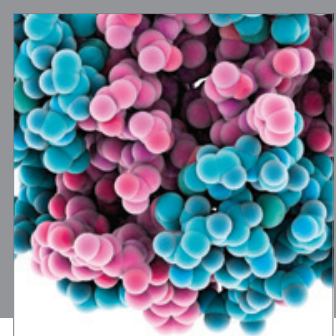

Journal of
Diabetes Research

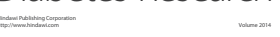

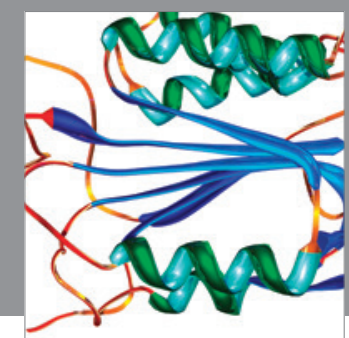

Disease Markers
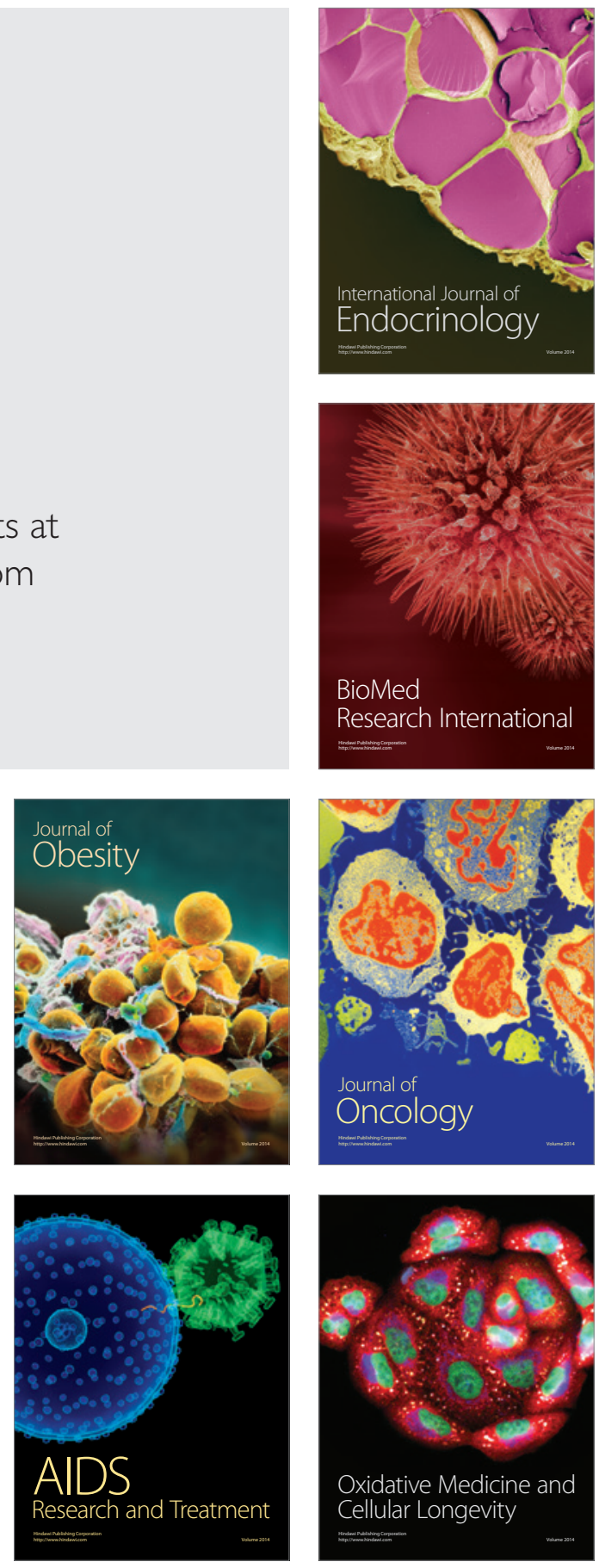